\title{
Retrospective and clinical studies of Marek's disease in Zaria, Nigeria
}

\author{
Musa I. W. ${ }^{1 \star}$, Bisalla M.. ${ }^{2}$, Mohammed B. ${ }^{3}$, Sa'idu L. ${ }^{4}$ and Abdu P. A. ${ }^{1}$ \\ ${ }^{1}$ Department of Veterinary Surgery and Medicine, Ahmadu Bello University, Zaria, Kaduna State, Nigeria. \\ ${ }^{2}$ Department of Veterinary Pathology and Microbiology, Ahmadu Bello University, Zaria, Kaduna State, Nigeria. \\ ${ }^{3}$ Department of Veterinary Public Health and Preventive Medicine, Ahmadu Bello University, Zaria, \\ Kaduna State, Nigeria. \\ ${ }^{4}$ Veterinary Teaching Hospital, Ahmadu Bello University, Zaria, Kaduna State, Nigeria.
}

Accepted 25 February, 2013

\begin{abstract}
A ten year retrospective study (2000-2009) of Marek's disease (MD) was conducted in the Veterinary Teaching Hospital, Ahmadu Bello University, Zaria. 3,039 different poultry diseases were recorded, MD represents $4.9 \% .63 \%$ of MD was recorded in birds 10 to 20 weeks old, $9.3 \%$ in birds above 30 weeks and $2.0 \%$ in birds below ten weeks. MD occurred mainly during the pre-rainy to rainy seasons with a progressive yearly increase. Strong association existed between season and MD $(p<0.05)$, risk estimate was also relevant (OR-2.4). A clinical analysis of birds affected with MD over the years revealed uneven growth and progressive weight loss as major complaints; ruffled feathers and whitishyellow diarrhea were the major observable signs. Major gross lesions were severe emaciation, thickened proventriculus and flabby heart with loss of coronary fats. Histopathology revealed focal to diffuse neoplastic lesions in the affected organs. MD mainly affected chickens aged 10 to 20 weeks. The disease is endemic and on the increase in Zaria and its environs. We recommend that an effective MD vaccination technique and schedule be established for this region, purchase of point of lay chickens for production should be discouraged and standard biosecurity measures must be enhanced in hatcheries and farms to prevent primary exposure.
\end{abstract}

Key words: Marek's disease, occurrence, diagnosis, Zaria.

\section{INTRODUCTION}

Consumption of poultry and poultry products in most developing countries has grown by $5.8 \%$, faster than that of human population growth; as a result, the poultry industry has over the years recorded dramatic changes (David, 2000). There is no doubt that high rate of intensification may suffer management defects by deteriorating standards, interplay between environment, host and organism genes, slow responses to prevention and treatment that may ultimately subject a large number of birds to further suffering with a consequent high rate of disease spread (David, 2000; Frank, 2001). Almost all

* Corresponding author. E-mail: ibwazkalt@yahoo.co.uk. Tel: +2348036658789. industrialized nations had at one time experienced losses due to Marek's disease (MD) in their poultry industry and a crude estimate of the cost of Marek's disease is said to be in the range of several billion US dollars (Calnek and Witter, 1997; David, 2000; Frank, 2001; Ionica and Comand, 2009; Katherine et al., 2011). Marek's disease is common in intensively managed commercial layer type chickens (Cauchy and Coudert, 1986; Dong et al., 2006; Graham, 1976; Stephen et al., 2008), though few reports have been documented in broilers and geese in some countries (Payne, 2004; Ionica and Coman, 2009). It is a transmissible lymphoproliferative disease of primarily chicken that is caused by an alpha herpes virus and characterized by malignant tumour formations in internal organs, skin, eye and peripheral nerves (Calnek and Witter, 1997; David, 2000; Dong et al., 2008; Graham, 
1976; Stephen et al., 2008). The Marek's disease virus (MDV) is cell associated in body organs and tumors, it replicates and exists as enveloped free form in the feather follicles making feathers particularly dander, dust and litter materials loaded with MD virus, thus facilitating virus transmission by air borne route (Calnek and Witter, 1997; Adene and Akpavie, 2004; Frank, 2001). Susceptible chickens infected with the pathogenic MDV suffer cytolysis of the lymphoid organs and a concomitant immunosuppression (Gordon, 1976; Frank, 2001). Such birds mainly die as a result of tumour development in the visceral organs and peripheral nerves (Frank, 2001). Though morbidity and mortality vary with virus strain (Graham, 1976; Cauchy and Coudert, 1986; Dong et al., 2008; Ionica and Coman, 2009), it is a major economic risk for poultry flocks, not only because of its worldwide distribution, but because it majorly affects young adults about to be utilized for meat or egg production, thereby reducing the profitability of an affected flock (Fatumbi and Adene, 1984; Frank, 2001).

Single vaccination against MD either in ovo or at day of hatch in genetically susceptible stock has been effectively used to control the occurrence of clinical disease in the recent pass (Gordon, 1979; Powel, 1981; Frank, 2001). But more recently, double vaccination against MD has also been reported to be more effective (Payne, 2004). However, the evolution of very virulent MD virus strains, inevitable exposure of flocks to other immunosuppressive diseases or conditions, exposure of birds to Marek's disease virus before vaccinal immunity develops and inappropriate vaccine handling and vaccination procedures have resulted to "vaccine break and failure" leading to increasing number of MD outbreaks despite consistent vaccination in many countries (Gordon, 1979; Frank, 2001; Payne, 2004). Another problem associated with MD control through vaccination is evaluating vaccine induced protection following vaccine administration (Frank, 2001).

The poultry industry in Nigeria is fast developing but with few hatcheries concentrated in some parts of the country (Fatumbi and Adene, 1984; Geidam et al., 2006; Olabode et al., 2009). Many outbreaks of poultry diseases have been directly or indirectly associated with high poultry farm concentrations (Cauchy and Coudert, 1986; Calnek and Witter, 1997; Frank, 2001). Such areas pose great risk of disease transmission even in the face of vaccination (Calnek and Witter, 1997). Few studies conducted on MD in Nigeria appear not to adequately address increasing MD outbreaks nationwide (Fatumbi and Adene, 1984; Adene and Akpavie, 2004; Akpavie, 2005; Olabode et al., 2009). A very low prevalence was recorded in Ibadan (Fatumbi and Adene, 1984), a 2.14\% prevalence rate was recorded for avian neoplastic diseases (MD inclusive) in Ilorin, Nigeria (Geidam et al., 2006), with the highest year of occurrence in 1998. From the available literature, this is the first paper that describes adequately the status of MD in Zaria, Nigeria as of 2009 .

\section{MATERIALS AND METHODS}

\section{Study area}

This study was conducted in Zaria which is located between longitude $11^{\circ} 07^{\prime} \mathrm{N}$ and latitude $7^{\circ} 44^{\prime} \mathrm{E}$ within the Sudan Savannah Zone. The average rainfall ranges from 1000 to $1250 \mathrm{~mm}$, diurnal temperature range of 17 to $33^{\circ} \mathrm{C}$ and vegetation cover of predominantly trees and grasses.

\section{Sample collection}

Carcases or live birds submitted to our poultry clinic that originated from mainly Kaduna State and occasionally from other neighbouring States (Kano, Katsina, Zamfara, Sokoto, Kebbi, Niger and Federal Capital Territory (FCT) Abuja) were used for the study. Each carcass was subjected to routine post-mortem examination paying attention to changes in size, colour and the transactional appearances that may be suggestive of neoplastic growth (Fatumbi and Adene, 1984). Two or more peripheral nerves were grossly examined and processed histopathologically to differentiate MD from avian leukosis (AL) (Fatumbi and Adene, 1984). Samples of liver, spleen, kidneys, proventriculus, skin, eye, muscle, schiatic nerve, gonads and bursas of fabricius either grossly affected by tumours or not were collected for histopathology examination. These samples were taken to Histopathology Laboratory of the Faculty of Veterinary Medicine, Ahmadu Bello University, Zaria for processing. Flock histories, clinical and pathological lesions observed in reported outbreaks stood as our bases to tentatively diagnose MD, while histopathology findings complemented the diagnoses.

\section{Histopathology}

Tissue samples collected were fixed in $10 \%$ neutral buffered formalin for 3 days, embedded in paraffin and sectioned with microtome $(5 \mu \mathrm{m})$. These were stained with haematoxylin eosin (HE) and examined under light microscope at 25 and $40 x$ magnifications for evidence of histological changes (Fatumbi and Adene, 1984; Baker et al., 2001; Ionica and Coman, 2009).

\section{Data collection}

A ten-year clinic record (2000-2009) of the Veterinary Teaching Hospital, Ahmadu Bello University, Zaria was utilised for this study. Data on season, year, month, breed and age were extracted. A case was considered as a farm that reported outbreak of a disease and diagnosed based on the history, clinical signs, post mortem findings and laboratory results. The age of birds in this study were categorised as follows: (i) 1 to 10 weeks (ii) 10 to 20 weeks (iii) 20 to 30 weeks (iv) $>30$ weeks while seasons in Zaria and environs were categorised as dry (January-March), pre-rainy (April-June), rainy (July-August), pre-dry (October-November) (Abdu et al., 1992). The monthly distribution of MD for the period under study (2000-2009) was reduced using the 10-year data to one year using the 12 months ratios to moving average method (Sa'idu et al., 2004).

\section{Data analysis}

Data generated were analysed statistically using Win-Episcope and 
Table 1. Yearly distribution of MD and other poultry diseases in Zaria.

\begin{tabular}{cccccc}
\hline Year & MD & NMD & Year spec. rate & OR & 95\% Cl on OR \\
\hline 2000 & 4 & 213 & 1.9 & 1.8 & $0.53-6.46$ \\
2001 & 6 & 350 & 1.7 & 1.4 & $0.41-4.47$ \\
2002 & 5 & 394 & 1.2 & 1 & \\
2003 & 4 & 150 & 2.7 & 2.1 & $0.56-7.93$ \\
2004 & 5 & 214 & 2.3 & 1.8 & $0.53-6.43$ \\
2005 & 8 & 182 & 4.4 & 3.5 & $1.12-10.73$ \\
2006 & 12 & 184 & 6.5 & 5.1 & $1.78-14.80$ \\
2007 & 19 & 296 & 6.4 & 5.1 & $1.87-13.70$ \\
2008 & 39 & 509 & 7.7 & 6.0 & $2.36-15.46$ \\
2009 & 48 & 397 & 12.1 & 9.5 & $3.75-24.18$ \\
2001 & 6 & 350 & 1.7 & 1.4 & $0.41-4.47$ \\
\hline
\end{tabular}

${ }^{*}$ Comparison point; MD- Marek's disease; NMD- Non-Marek's disease; spec. specific.

Table 2. Monthly distribution of MD and other poultry disease in Zaria.

\begin{tabular}{lccccc}
\hline Month & MD & NMD & Month spec. Rate & OR & 95\% Cl on OR \\
\hline Jan & 11 & 211 & 5.2 & 2.4 & $0.94-5.97$ \\
Feb & 11 & 152 & 7.2 & 3.2 & $1.28-8.25$ \\
Mar & 12 & 249 & 4.8 & 2.2 & $0.87-5.37$ \\
Apr & 17 & 261 & 6.5 & 2.9 & $1.25-6.93$ \\
May & 15 & 294 & 5.1 & 2.3 & $0.96-5.48$ \\
Jun & 25 & 310 & 8.1 & 3.6 & $1.61-8.14$ \\
Jul & 9 & 326 & 2.8 & 1.2 & $0.47-3.25$ \\
Aug & 10 & 359 & 2.2 & 1 & \\
Sep & 16 & 339 & 4.7 & 2.1 & $0.90-5.01$ \\
Oct & 8 & 213 & 3.7 & 1.7 & $0.63-4.60$ \\
Nov & 7 & 174 & 2.9 & 1.3 & $0.42-4.00$ \\
Dec & 9 & 151 & 6.0 & 2.7 & $1.03-7.16$ \\
Total & 150 & 3039 & & & \\
\hline
\end{tabular}

*Point of comparison; MD- Marek's disease; NMD- Non-Marek's disease; spec. specific.

SPSS statistical package (version 16.0) for windows.

\section{RESULTS}

Table 1 shows a total of 150 MD cases out of 3,039 poultry diseases recorded over a period of ten years (2000-2009) amounting to a $4.9 \%$ MD prevalence in Zaria, Nigeria. The incidence of MD was lowest (1.7) in the year 2001 and progressively increased to (12.1\%) in the year 2009.

The pre-rainy $(2.1 \%)$ and rainy $(1.4 \%)$ seasons in this study appear to have more cases of MD (Table 3). Two high monthly incidences occurred in February $(7.2 \%)$ and June $(8.1 \%)$ (Table 2). The favourable age for MD occurrence was seen to be 11 to 20 weeks (68\%) (Table
4). Pearsons chi-square test established significant association between season and the disease occurrence $(p<0.05)$, while estimated relative risk showed the prerainy season to be most significant (odds ratio-2.4) using the pre-dry season as reference point (Table $3, X^{2}=18.8$; $\mathrm{df}=3$ ). All the cases involved commercial improved breeds of chickens and no case of MD was recorded in the indigenous breeds of chickens or even wild birds. Table 5 shows the common and rare clinical and pathological lesions associated with Marek's disease in the study area. History revealed that farmers usually began to suspect a problem in their flocks when they noticed significant non-uniform growth and light weight in the flocks despite adequate feeding. From history, vaccination against MD was almost always questionable because farmers believed that MD vaccination was the 
Table 3. Seasonal distribution of MD in Zaria.

\begin{tabular}{cccccl}
\hline 95\% Cl on OR & OR & Season specific rate & NMD & MD & Season \\
\hline $0.67-2.12$ & 1.2 & 0.9 & 603 & 25 & Dry(Jan-Mar) \\
$1.46-3.90$ & 2.4 & 2.1 & 746 & 62 & Pre-rainy(Apr-Jun) \\
$0.78-2.21$ & 1.3 & 1.4 & 879 & 40 & Rainy(Jul-Sep) \\
& 1 & 0.8 & 661 & 23 & Pre-dry(Oct-Dec) \\
\hline
\end{tabular}

Table 4. Age and breed specific rates of MD.

\begin{tabular}{lcc}
\hline Age (weeks) & MD & Age/breed specific rate \\
\hline $1-10$ & 3 & 2.3 \\
$11-20$ & 102 & 68.0 \\
$21-30$ & 31 & 20.7 \\
$>30$ & 14 & 9.3 \\
Breed & & \\
Improved & 150 & 100 \\
Local & 0 & \\
\hline
\end{tabular}

responsibility of the hatchery, while few farmers revaccinated irrespective of whether MD vaccine was given at the hatchery or not. The consistent clinical signs observed where whitish-yellow diarrhoea and ruffled feathers; nervous signs which is characteristic of MD were rarely seen. The gross lesions observed in most cases were severe emaciation, flabby heart, distended gall bladder with bile and thickened proventriculus (Figures 1 to 3). Tumour growths in affected organs were also rarely seen. Microscopically, focal to diffuse infiltration or proliferation of immature and mature lymphocytes in the affected organs were consistent lesions (Plates 1 and 2).

\section{DISCUSSION}

Since the 1960s, increasingly virulent strains of MDV have caused continued poultry industry production losses worldwide (Graham, 1976; Cauchy and Coudert, 1986; Payne, 2004; Dong et al., 2008; Stephen et al., 2008; Katherine et al., 2011). In developing countries in addition, improper handling and administration of MD vaccines contribute to continuous outbreaks. This is because Marek's disease vaccine especially the cell associated type is the most sensitive vaccine requiring storage at $-196^{\circ} \mathrm{C}$ until use, and administration of reconstituted vaccine must be within the first two hours (Frank, 2001). However, the prevalence of MD is generally considered to be low and rarely exceeds $5 \%$ (Fatumbi and Adene, 1984; Frank, 2001; Dong et al., 2008). A study conducted in 2009 established a $2.14 \%$ prevalence rate of avian neoplasm in Ilorin, Nigeria (Olabode et al., 2009). Within the same year in this study, a prevalence rate of $4.9 \%$ for MD is established in Zaria. We have observed in addition, a progressive increase of MD incidences over the years with the lowest incidence $(2.5 \%)$ in 2000 and highest (12.1\%) in 2009. Accordingly, it has further been documented that for most countries of the world, MD outbreaks have been on the increase despite vaccination (Frank, 2001; Adene and Akpavie, 2004).

One other major issue of continuous MD outbreaks in the developing countries is that of vaccine handling. $A$ prevalence study of MD in indigenous and exotic chickens had 2 peaks of high prevalence in 1977 and 1983 in Nigeria, while 3 times rise of MD outbreaks occurred between 1976 and 1982 in the US (Adene and Akpavie, 2004). In our study, we noticed 2 peaks of high monthly incidences in February (7.2\%) and June (8.1\%) in Zaria. In support of this, the incidence of MD continued to increase at intervals of few years worldwide despite increasing efforts to control it due mainly to MD virus mutations leading to its increasing virulence (Payne, 2004; Katherine et al., 2011). This allows MD virus mutants to break through the protection afforded by the vaccine in use (Payne, 2004).

From this study, the highest likelihood of MD occurrence in Zaria is in the pre-rainy season which may be due to the fact that in the study area the dry season that precedes the pre-rainy is characterised by cold temperatures and high wind velocity which usually favour virus survival and the most important route (air borne) of MDV transmission (Fatumbi and Adene, 1984; Frank, 2001) and since MD has an incubation period of at least 3 weeks to several months, the exposure of most birds to MDV may have occurred during the pre-dry to dry seasons followed by the manifestation of lesions in the pre-rainy and rainy seasons. In addition, the pre-rainy season in the study area is characterised by high ambient temperatures which is a serious stressful factor to birds and may have devastating effects on the birds' immune system.

The age group mainly affected by MD in this study is 11 to 20 weeks $(68 \%)$. This is in agreement with the findings of many authors where 12 to 24 weeks were the age range mostly affected by clinical MD manifestations and MD rarely occurred above 24 weeks (Fatumbi and Adene, 1984; Cauchy and Coudert, 1986; Adene and Akpavie, 2004; Akpavie, 2005). This observation may not be unconnected with the long incubation period of MD 
Table 5. Clinical and pathological features of MD in randomly selected poultry farms located in Zaria and environs.

\begin{tabular}{|c|c|c|c|c|c|c|c|c|c|c|}
\hline \multirow{2}{*}{ Case features } & \multicolumn{10}{|c|}{ Case location (farms) } \\
\hline & A & B & C & $\mathbf{E}$ & $\mathbf{F}$ & $\mathbf{G}$ & $\mathbf{H}$ & I & $\mathbf{J}$ & $\mathbf{K}$ \\
\hline \multicolumn{11}{|l|}{ Case history } \\
\hline Uneven growth & + & + & + & + & + & + & + & + & + & + \\
\hline Light weight & + & + & + & + & + & + & + & + & + & + \\
\hline MD vaccination status & + & $?$ & $?$ & $?$ & $?$ & $?$ & + & $?$ & $?$ & $?$ \\
\hline \multicolumn{11}{|l|}{ Clinical signs } \\
\hline Whitish-yellow diarrhoea & + & + & + & + & + & + & + & + & + & + \\
\hline Nervous signs & - & - & + & + & - & - & - & - & + & - \\
\hline Ruffled feathers & + & + & + & + & + & + & + & + & + & + \\
\hline Inconsistent signs & + & + & + & + & + & + & + & + & + & + \\
\hline \multicolumn{11}{|l|}{ Gross lesions } \\
\hline Emaciated carcass & + & + & + & + & + & + & + & + & + & + \\
\hline Distended gall bladder & + & + & + & + & + & + & + & + & + & + \\
\hline Enlarged/thickened proventriculus & + & + & + & + & + & + & + & + & + & + \\
\hline Flabby heart with loss of coronary fats & + & + & + & + & + & + & + & + & + & + \\
\hline Tumours in affected organs & + & - & - & + & + & + & - & + & - & - \\
\hline Inconsistent lesions & + & + & + & + & + & + & + & + & + & + \\
\hline \multicolumn{11}{|l|}{ Histopathology } \\
\hline Focal to diffuse organ infiltration/proliferation of lymphocytes, lymphoblasts, plasma cells & + & + & + & + & + & + & + & + & + & + \\
\hline
\end{tabular}

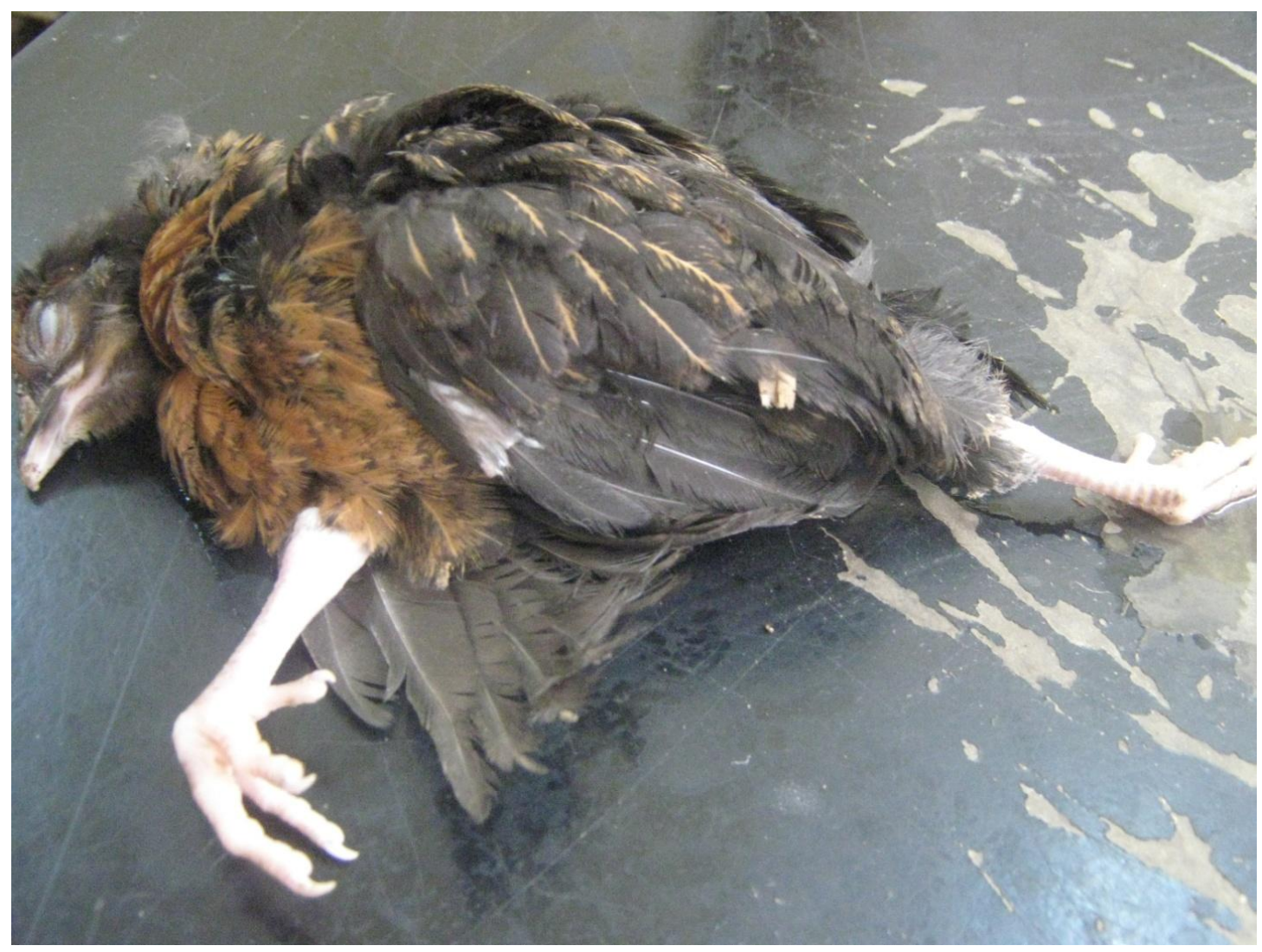

Figure 1. Marek's disease infected 6 week-old commercial chicken showing leg paralysis and ruffled feathers. 


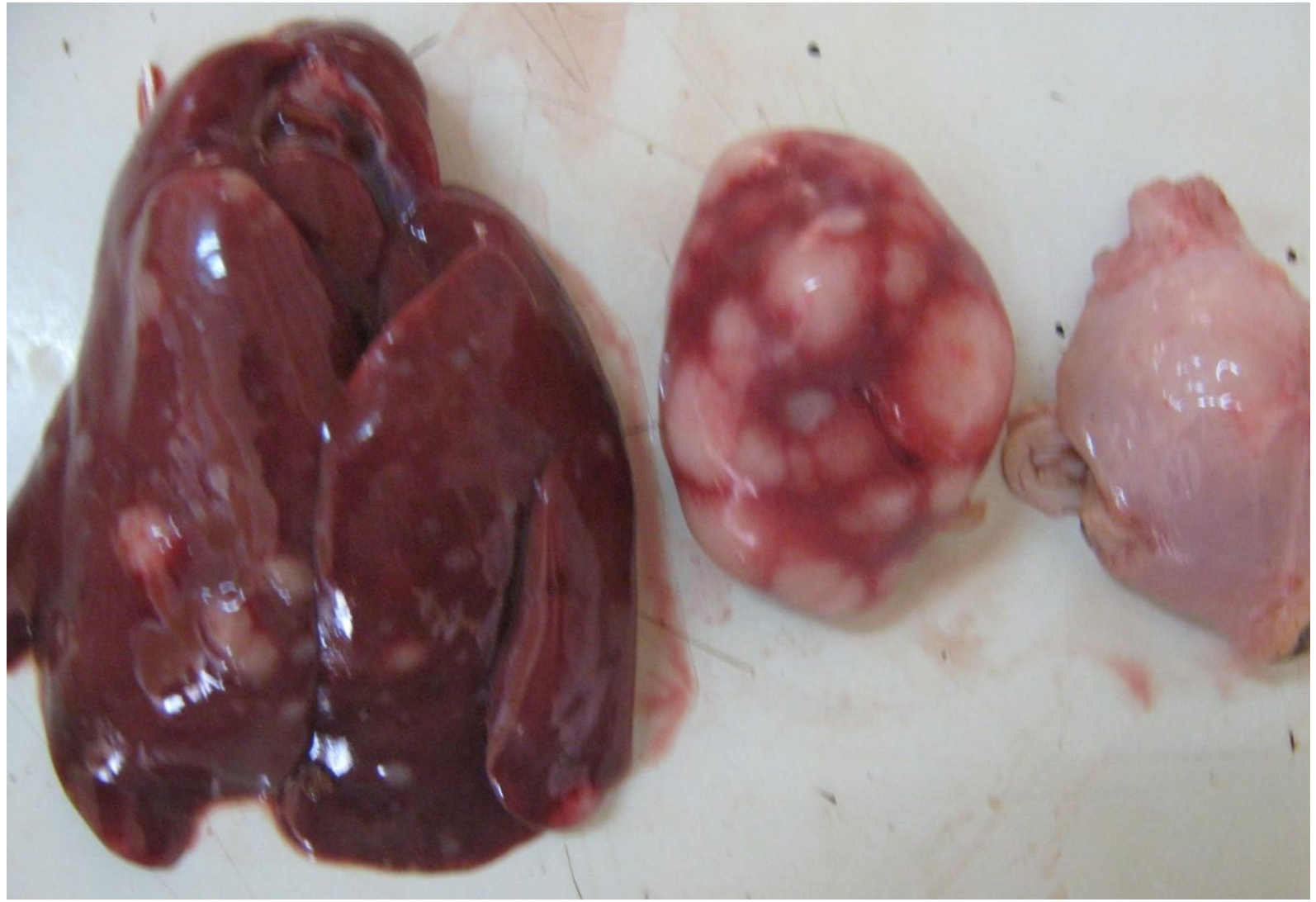

Figure 2. From left to right: whitish nodular neoplastic growths in the liver and spleen and enlarged proventriculus in MD infected 17 week-old commercial layer chicken.

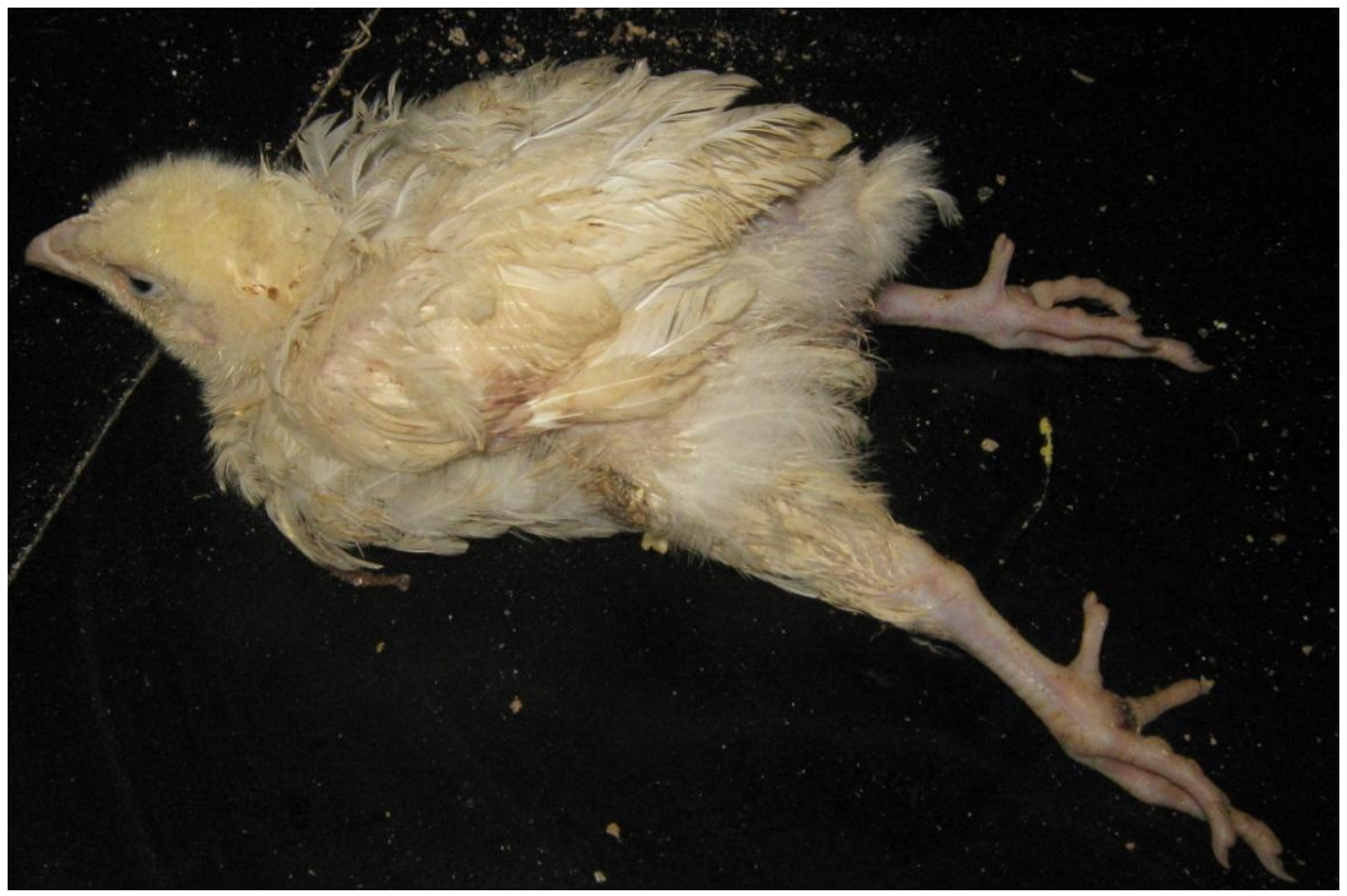

Figure 3. MD affected 3 week-old pullet showing bilateral leg paralysis. 


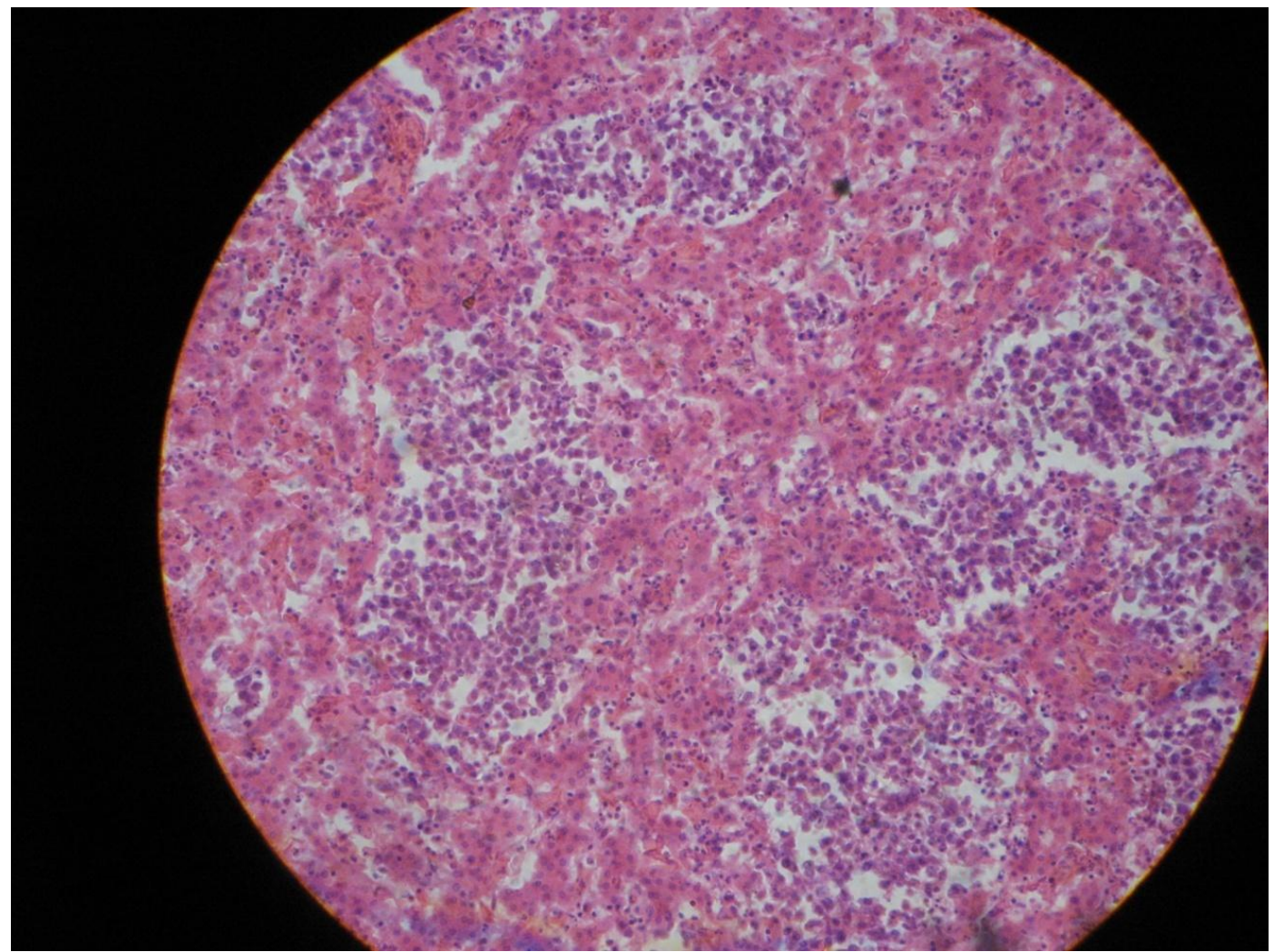

Plate 1. Diffuse infiltration of immature lymphocytes in the liver of MD infected chicken.

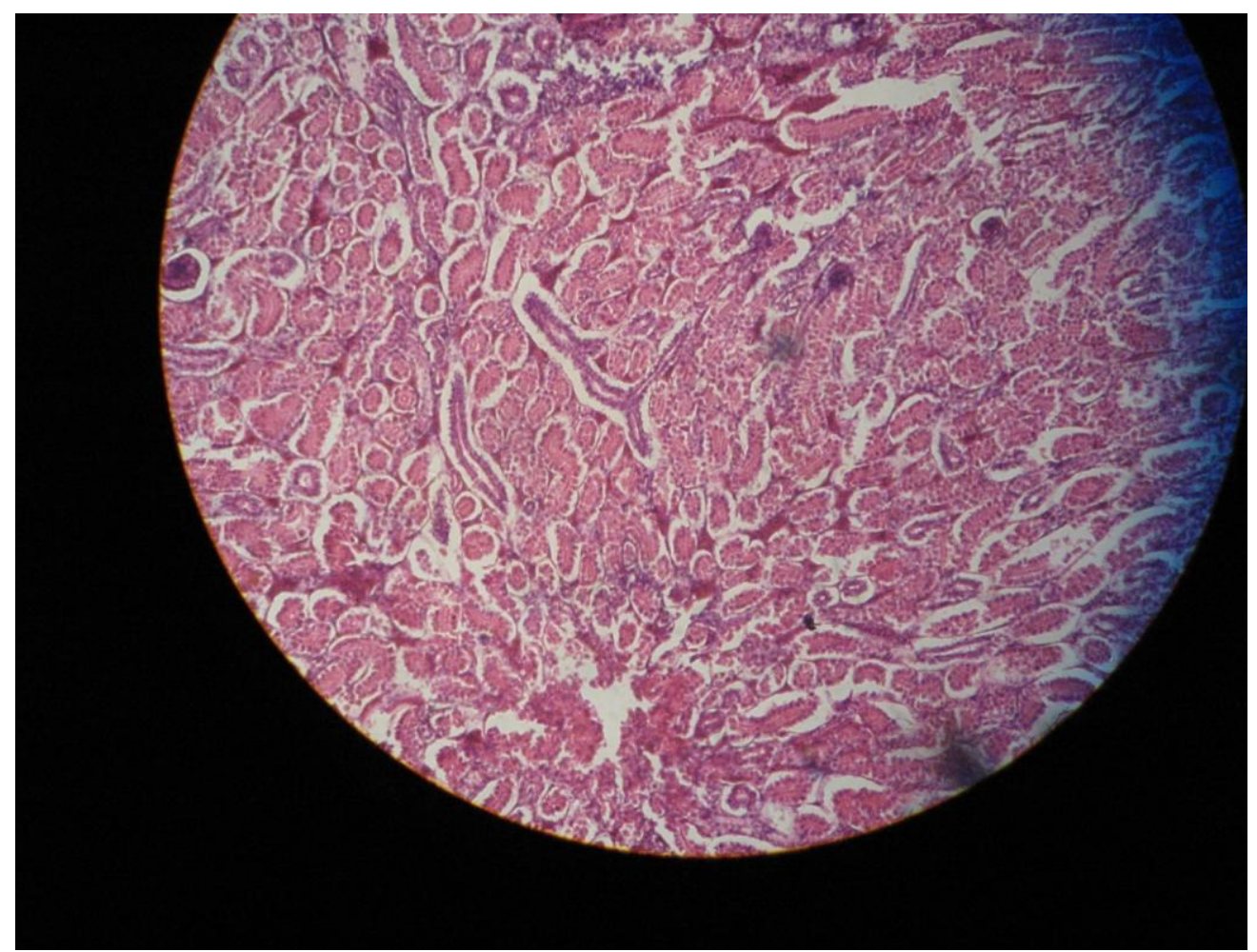

Plate 2. Diffuse infiltration of lymphocytes in the kidney of MD infected chicken. 
(weeks to several months) being a chronic cancerous disease, so birds exposed at an early age may begin to show clinical disease at a much later age. Also, poultry are kept on low nutritive but high energy grower feed within this age range (9 weeks to point of lay) in most farms worldwide. Therefore, bird's immune response is not at its best to protect against this avian cancer and most other immunosuppressive conditions. In addition, the MD virus is reported to lie latent until a later age when birds are beginning to lay (Fatumbi and Adene, 1984; Frank, 2001).

All the cases of MD recorded in this study were in exotic egg producing type breeds (100\%) and non in broilers or indigenous breeds or wild bird species. Meanwhile Nigerian indigenous chickens have only been shown to be seropositive despite their significance in the nation's poultry population (Adene and Akpavie, 2004). Should this be the situation, one will suspect that Nigerian indigenous breeds may possess some levels of genetic resistant to $\mathrm{MD}$, and or $\mathrm{MD}$ may be only significant under intensive management systems since Nigerian indigenous breeds are mainly kept on extensive system of management. Accordingly, it has earlier been reported that certain exotic breeds of chickens have been shown to resist MDV (Cauchy and Coudert, 1986; Frank, 2001; Adene and Akpavie, 2004). From the available literature, there has not been any documented report of MD in broilers in Nigeria. Few reports and seasonal incidences of MD were observed in broiler flocks in other few countries (Calnek and Witter, 1997; Ionica and Coman, 2009) while high losses were reported in intensively managed broiler flocks (Calnek and Witter, 1997).

The predominant complaints of flock owners were uneven growth of their birds and inability to put on weight. Clinical observations often revealed weight loss and ruffled feathers. Gross lesions of emaciation and flabby heart with loss of coronary fats were consistently observed. Other important diagnostic lesions identified were principally neoplastic affecting many organs and tissues but these were predominantly observed in older birds as earlier reported (Fatumbi and Adene, 1984; Cauchy and Coudert, 1986; Frank, 2001).

Clinical manifestations of MD vary with the form of MD virus infection and where the lesions primarily develop in the host (Cauchy and Coudert, 1986; Stephen et al., 2008).

Flock history (age of birds), organ/and or tissue neoplastic gross lesions, peripheral nerve lesions and histopathology findings have been our strong diagnostic evidences of MD in the clinic as reported by others (Fatumbi and Adene, 1984; Cauchy and Coudert, 1986; Calnek and Witter, 1997) as serology or viral antigen detection might not in our situation differentiate between vaccine and field strains. Nervous signs have not been consistent in assisting the MD diagnosis in our environment, thereby posing further difficulty in differentiating it from avian leukosis. It has earlier been documented that only a small proportion of the MD affected flocks show nervous signs (Cauchy and Coudert, 1986) and that morbidity, mortality rates and other gross manifestations of MD may vary with virus strain, immune status, age and sex of the host (Calnek and Witter, 1997; Frank, 2001).

We have consistently observed initial MD cases presented with uneven growth, emaciated carcasses and enlarged/thickened proventriculus in birds less than 10 weeks old before visceral tumours fully developed. Such birds may not show any additional classical gross lesions suggestive of MD; but were later returned with fully blown MD gross lesions weeks after first presentation. Meanwhile swelling of the proventriculus has been reported to be one of the classical signs of MD (Frank, 2001).

Available research showed that many host, environmental and management factors do modify the expression of MD (Graham, 1976; Cauchy and Coudert, 1986; Stephen, 2008). It is not the same in all birds, and may vary during spread within a flock, also between flocks and from one region to another (Frank, 2001; Stephen et al., 2008). It is therefore difficult to provide an overall field description of Marek's disease (Cauchy, 1986; Stephen et al., 2008). This is why there is an "acute" form which is more severe in symptoms and lesions than the "classical" form which is close to the original description and such descriptions were based on the disease as it occurred in unvaccinated flocks (Frank, 2001; Stephen et al., 2008).

\section{Conclusion}

From this report, it is clear that MD is on the increase despite farmer's efforts to prevent and control it through vaccination. Vaccination alone is therefore not completely reliable in preventing MD outbreaks. Intensive research should be carried out to develop a more potent user friendly MD vaccine, while for the time being, high hygienic standards should be maintained at the hatcheries and farms, and poultry breeds that are known for their resistant to MD should be encouraged to be kept by farmers.

\section{ACKNOWLEDGEMENTS}

The authors thank the technical staff of the poultry VTH$A B U$ clinic and histopathology laboratory for making available the required records and processing the tissue slides.

\section{REFERENCES}

ABDU PA, MERA UM, SA'IDU L (1992). A study of chicken mortality in 
Zaria Nigeria. Proceedings of National Workshop on Livestock and Veterinary Services, Vom, Nigeria pp. 51-55.

Adene DF, Akpavie SO (2004). An overview of Marek's disease and the options in its control. Poultry Health and Production Principles and Practices. Stering Horden Publishers Nig. LTD. Ibadan, Nigeria. pp. 107-127.

Akpavie SO (2005). Major neoplasm's of poultry with special emphasis on the pathology, diagnosis and control of Marek's disease and Leucosis-J. Proceedings Poultry Health and Production Efficiency and Satellite Colloquium on Avian Flu. Workshop on improved disease diagnosis, health nutrition and risk management practices in poultry production efficiency, Zaria. pp. 26-30.

Baker FJ, Silverton RE, Palister CJ (2001). Cellular pathology. Introduction to Medical Laboratory Technology, $7^{\text {th }}$ Edition. Bounty Press Limited, Nigeria. pp. 175-248.

Calnek BW, Witter RL (1997). Marek's disease. In Calnek, B.W, Barnes, J.H. Beard, C.W. LARRY, R.M and SAIF, Y.M. eds. Diseases of Poultry, $9^{\text {th }}$ ed. lowa State University Press, lowa. pp. 356-430

Cauchy L, Coudert F (1986). Marek's disease. Rev. Sci. Tech. Int Off des Epiz. 5:1025-1035.

David S (2000). Marek's disease and leukosis. Poultry health and management, $4^{\text {th }}$ edn. Blackwell Publishers, Cowley road Oxford. pp. 235-238.

Dong H, Kumar PM, Tavlarides-Hontz P, Arumugaswami V, Jarosinski K, Osterrieder N, and Parcells MS (2008). The Meq oncoprotein of Marek's disease virus: Mutations in high virulence MDVs and their putative role in changing pathogenesis. Proceedings of the $80^{\mathrm{TH}}$ Northeastern Conference on Avian Diseases. State College, PA, USA 2008, www.ivis.org. pp. 1-2.

Fatumbi OO, Adene DF (1984). A ten year prevalence study of Marek's disease and avian leukosis at Ibadan, Nigeria. Acta Vet. Brno. 55:4953 .
Frank F (2001). Marek's disease: History, actual and future Perspectives. Lohmann Inform. No. 25, pp. 1-5.

Geidam YA, Bukar MM, Ambali AG (2006). Chick quality control, a key to sustainable poultry production Nigeria. Nig. Vet. J. 27:1-6.

Gordon RF (1979). Poultry disease. Bulliere Tindall, London. 2:80.

Graham H (1976). Prevention of mareks disease, a review. Can. Res. 36:696-700.

Ionica FM, Coman NC (2009). An outbreak of Marek's disease in broiler chickens: Epidemiological, clinical and anatomopathological aspects. Luc. Sti. Med. Vet. 1:224-227.

Katherine EA, Andrew FR, Nicholas JS, Katrin G, Stephen WW, Mark EJW (2011). Modelling Marek's Disease Virus infection, parameter estimates for mortality rate and infectiousness. Vet. Res. 2:52-55.

Olabode HOK, Jwander LD, Moses GD, Ighadalo E, Egbaidome SA (2009). Prevalence of Avian Leucosis and MAREK'S disease in Ilorin, Kwara State, Nigeria. Nig. Vet. J. 30:64-68.

Powel PC (1981). Immunity to Marek's Disease. In Rose, M.E. Payne, L.N. and Freeman, B.M. (Eds). Avian Immunology, Poultry Science Symposium number sixteen. pp. 263-283.

Sa'id L, Abdu PA, Tekdek LB, Umoh, JU (2004). Retrospective study of Newcastle disease cases in Zaria, Nigeria. Nig. Vet. J. 27:53-56.

Stephen L, Claire K, Philip H (2008). Marek's disease-a silent enemy. Bri. Free Range Egg Prod. Ass. pp. 1-5.

Payne $L$ (2004). Understanding Marek's disease. Proceedings of the $7^{\text {th }}$ International Marek's Disease Symposium, Catherine's College, Oxford, England pp.1-4. 